Accepted version:

Boud, D., Costley, C., Marshall, S. and Sutton, B. (published online 21 May 2020). Impacts of a professional practice doctorate: a collaborative enquiry. Higher Education Research and

Development, DOI: 10.1080/07294360.2020.1765744

\section{Impacts of a professional practice doctorate: a collaborative enquiry}

David Boud ${ }^{1,2 .}$

Carol Costley ${ }^{1}$

Steve Marshall

Brian Sutton ${ }^{1}$

${ }^{1}$ Middlesex University, ${ }^{2}$ Deakin University, ${ }^{3}$ University of Technology Sydney, ${ }^{4} \mathrm{Hult}$ Ashridge Executive Education

David Boud http://orcid.org/0000-0002-6883-2722

- $996-8908$

Steve Marshall https://orcid.org/0000-0002-2527-3887

\section{Abstract}

Doctoral education aims to benefit those who undertake it, but does it exert a wider influence? Professional doctorates are commonly designed to have an impact beyond the individual concerned, but is this influence realised? This paper focuses on a collaborative enquiry by a group of academics and doctoral alumni from non-discipline-specific professional doctorates. The enquiry examined how the professional practice of the praduates chang as a rosut of the and their professon. It found that there was cons the alu the alumi, but the

Key words: doctoral education, research impact, collaborative enquiry, professional practice

It is within the context of the emerging accountability discourse of impact that this paper is positioned. Governments have, in research assessment exercises that influence university funding, demanded that research be judged in terms of its impact beyond the academy (e.g. Excellence in Research Australia [ERA], 2018). Applying such a discourse to doctorates, we can ask, in what ways does the completion of a doctorate make a difference to people and things beyond the graduate themselves? While there have been previous studies undertaken about the influence of doctoral education on the lives of the individuals enrolled (e.g. Wellington and Sikes, 2006; Stephenson, Malloch \& Cairns, 2006), the present study is part of a much smaller set that focuses on the wider impact of a doctorate on the work and professional activities of the graduate. While any single doctoral study may not have a discernible impact, given that the rationale of professional doctorates is that they are close to and seek to influence practice, overall there should be clear traces of influence from them on the possible resolution of complex problems, social justice and the wider good.
The paper focuses on work-based, transdisciplinary professional doctorates that use the exigencies of work as the centrepoint of studies. Such doctorates are a subset of the wider set exigence of professionas dictes recent study of graduates fom one of these programmes, Boud, Fillery-Travis, Pizzolato and Sutton (2018) explored influences on practice through the examintion of project reports and post-graduation interviews. They noted that evidence of impact on practice was not an explicit criterion of the examination process, nor was it a requirement for graduation, nevertheless there were multiple signs of influence on organisations and professional contexts. What that study was unable to do, but is provided here, is to look at wider effects post-graduation, and ascertain continuing impact through the eyes of the graduates.

A common rationale of professional doctorates is that they build capacity to undertake research in candidates own professional contexts. We utilize this in the present paper by involving graduates from two such programmes in a collaborative enquiry into the ways in which their doctorate influenced their own professional practice and that of others. If they had developed research capacity to operate within their own context, they should be able to use it to study the influence of their work and use their insider perspectives to make sense of what they encounter. The collaborative enquiry took the form of a group of academics (the what they working with volunteer gradutes, now spread across many countries, to uns (the project with the graduates as co-researchers as well as subjects in their own study. This project with the graduates as co-researchers as well as subjects in their own study. This questions to be addressed in the investigation, developing a research approach and engaging wiestions to be addressed

Following a discussion of the literature on the influence of professional doctorates, the paper outlines the form of collaborative enquiry used. It describes the processes used by the enquiry group to identify research questions and the data needed to address them. It focuses on the data analysis process and how the team reached consensus on the findings.

Background

The impact of research has become a central feature of national research policy discourse. The UK's Research Excellence Framework (REF), for example, defines impact as an effect on change or benefit to the economy, society, culture, public policy or services, health the environment or quality of life, beyond academia. It has been recognised as:

The impact of research, be it academic, economic and social can include:

Instrumental: influencing the development of policy, practice or service provision,

shaping legislation, altering behaviour. Conceptual: contributing to the

understanding of policy issues, reframing debates. Capacity building : through

technical and personal skill development.

Economic and Social Research Council [ESRC], 2019

This served as the working definition of impact in the present study.

While impact is being reported at the level of research groups and institutions through measures such as those found in the REF or the ERA (2018) exercise, less emphasis has been focussed on systematically reporting this for individual instances of research, either for academic researchers or for research students. However, there have been a number of studies reported in the literature that have focused on the impact of doctoral study. 
Definitional problems of what constitutes impact persist and McSherry et al's (2019) international study asks for more definition of the impacts and outcomes. They found the meanings of these terms were ambiguous, yet impact and outcome measures now constitute evidence for quality assurance for academic reviewers, employers, professional regulators and other stakeholders.

The discourse of impact implies a separation between research and its effects, as if knowledge were produced and then disseminated. In many cases it might be more fruitful to think in terms of what has become known as knowledge exchange, even though this representation can tend to objectify the knowledge involved. Exchanging experiences, data ideas and reflections between researchers, co-researchers and other stakeholders in professional doctorate education is central in producing significant research that recognises enabling steps towards and outcomes of impact for the public good: ".. good Knowledge Exchange is as much about approach, mindset, personal qualities and researcher mission" (UK Research and Innovation [UKRI] 2016)

A 'pathways to impact' view of undertaking research incorporates the principles and practice of the co-production of knowledge rather than dissemination. This means that the approach to research should have a broud scope with engagement with wider stakeholders in the research (1) 政 identified in pathways to impact (ESRC, 2019b).

Studies of the impact of doctoral studies have found substantial personal impact on those undertaking them (Wellington and Sikes, 2006; Lee, Brennan and Green, 2009). Stephenson, Malloch and Cairns (2006), for example, found that doctoral candidates as employees developed newfound confidence, greater insight, empowerment, a greater overview of how things worked, writing and research skills and personal impact. Although any kind of doctorate might have a personal effect that could lead to professional impacts, most studies are usually concerned with practitioners who become researchers. When practitioners already employed undertake a concurrent doctorate to further already high-level professional work, their positionality, ability to form networks, professional knowledge and experience combines with the academic experience enabling different kinds of impact. Lester (2012) examined a selection of theses from a large professional doctorate programme to identify how new knowledge was being attained where practitioners were investigating practices in their own professional field. He found that they:

collectively indicate that practice-based issues can provide fertile ground for stimulating the production of knowledge that has relevance far beyond the immediate context, and that the workplace can act as a site of significant knowledge-generation when live issues are responded to and reflected upon with intellectual rigour. (p 12)

The impact on the individual cannot readily be separated from wider effects of the doctorate. Fox and Slade (2014), for example, identified the development of the graduates' conceptual frameworks, increased personal and professional confidence, enhanced engagement within and beyond their organisations and building of improved networks. However, they found no straightforward links between undertaking the doctorate and achieving organisational impact due to the complexity and messiness of the professional learning process. Similarly, Costley and Abukari (2015) found that professional doctorate graduates were enabled to make and Abukari (2015) found that professional doctorate graduates were enabled to make
organisational change due to their professional colleagues perceiving them as more credible.
They were more self-assured in their own abilities to work at a high level, they had influence because they were in a position to be in control of the process and they were more prepared to work independently, be self-critical and put themselves into their professional work whils addressing the academic work needed for the doctorate. In a similar programme Boud et al (2018) found that graduates' reputation and circle of influence coupled with their practitioner research experience on the doctorate enabled impact often across organisational and research experience on the

While there have been studies of the impact of doctorates, there are significant gaps in the literature. Hawkes and Yerrabati (2018) suggested that there is a wider value, not well documented in the literature. This concurs with a British report on professional doctorates: Although the PD is grounded in professional practice, there is little robust evidence of impact on professional practice and changes in the workplace. More research could usefully be done to explore these impacts. Mellors-Bourne, Robinson and Metcalfe, (2016, p. 67)

The growing literature on impact can enable universities to start to track the influence of research as it occurs, both on others and on the practice of the candidate/graduate. This has become a growing focus for curriculum development. For example, Kumar's (2014) documentation of impact in a new Doctor of Education modelled on the Carnegie Project on the Education Doctorate (Perry \& Zambo, 2018) in the United States found methodological approaches are often key to dem approaches a often kectorate research. An emphasis on illustrated through paying attention to definition of problems and providing recommendations
for stakeholder groups (Armsby, Costley \& Cranfield, 2018).

Higher education is expected not only to contribute to professional qualifications but to the public good. There is a need, as East, Stokes and Walker (2014) argue, to go beyond a narrow economic understanding of the public good or instrumental interpretation of graduate 'attributes', to follow a human development and capabilities approach. In relation to the social purposes of professional doctorates this centres on the development of practitionerresearchers as agents of social action and change through production of knowledge that could lead to increased impact and achievement of social justice. There is a tension between private and public good however, and Armsby et al (2018) found the 'values and purposes' of professional doctorates were perceived as a private good regarding development of candidates' personal and professional knowledge, and as contributing to the public good through practitioners' research and social actions aiming to have real-world impact. With experienced professionals as candidates, inclusion of their expertise in a nuanced evaluation experienced prossiontion overall approach and impact on an area of practice knowledge.

From this literature, we have ascertained that there is a need for more nuanced research into the impact of professional doctorates. The values and purposes of professional doctorates have been identified in order to determine the rationale for making impact and the kinds of impact possible in this wide range of contexts. The study of impact is moving from an emphasis on the personal to wider social and economic impact and this is emphasised in the current study. 
Collaborative enquiry

Many conventional models of research place the researcher outside the situation or group under examination. The researchers are imagined to be 'looking in' at their subjects, careful to remain 'unbiased' in their observation of the unfolding circumstances. In contrast, various forms of practitioner research firmly situate the researcher as part of the issue or context under consideration; importantly, "they are part of the situation they want to understand and change" (Townsend 2013, p. 32).

Within this broad model of 'insider' research, the collaborative approach adopted here rests within a group of participatory action research methods including human inquiry,

collaborative inquiry, action inquiry and cooperative inquiry (Greenwood \& Levin, 2007). The primary orientation of action research is to produce practical knowing as a product of emergent, collaborative inquiry which aims to enhance people's involvement in the generation of knowledge about them and their work (Coghlan 2007). Such approaches place a strong value on personal, lived experience and engagement, where a research question is devised through dialogue and members of the research group carry out cycles of action (outside the group) and reflection (inside the group) (Coleman, 2019).

Tensions within participative research modalities frequently relate to issues of power, control and social justice, which pose questions of "whose inquiry?" and "to what end?"

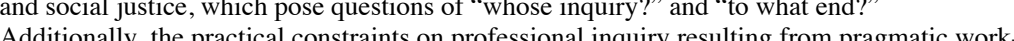
Additionally, the practical constraints on professional inquiry resulting from pragmatic workbased limita for a sustained peniod of enggenent (Drew, Priestley, \& Miche, 2015). We found that each of these issues arose in our study as pragmatic considerations which meant that we were effectively split into two groups; one guiding the of their lived experience.

The collaborative structure for our research project comprised a group of four faculty working with alumni (most of whom they had not supervised) from two Doctor of Professional Studies (DProf) programmes to understand their effects. While both programmes held their focus of inquiry on professional practice, one described itself as interprofessional, transdisciplinary and the other explicitly as a post conventional, action research doctorate. Both programmes were designed as fully work-based, that is except for brief activities on campus, candidature was part-time, and they studied in their places of work. The faculty group held periodic virtual meetings to review progress and overall trajectory of the inquiry, whereas the alumni group, who were more disparate in their process and locations (currently practising in the UK, Canada the West Indies, Singapore and Egypt), provided (currenty practising in the UK, Cance , the Full doc chang Full documentation of all contributions at each stage of the enquiry were kept as shared files on a drive accessible to both groups. The study started in 2018, but most of the data was
collected in 2019 .

Approach to the enquiry

The faculty group sought to engage the alumni as co-researchers both in designing the study as well as carrying it out. Prior to approaching prospective participants formal ethics

approval was gained from the university. Approaches were made via an initial email to all graduates from each programme. This resulted in ten alumni who started the process; by the end of the stages reported here, seven remained active. See Table 1 for the co-researchers who completed the final cycle and titles of their work. Each approved their name be used in this paper. The present paper draws on the material of the enquiry but was written by the faculty members. Co-researchers read and commented on the draft of the paper and authorship proposed, but this did not lead to any changes of substance.

\begin{tabular}{|l|l|c|}
\hline \multicolumn{1}{|c|}{ Co-Researcher } & \multicolumn{1}{|c|}{ Doctorate Title } & Year \\
\hline Chijioke Agomo & $\begin{array}{l}\text { Strategies enhancing the public health role of community } \\
\text { pharmacists in the UK. }\end{array}$ & 2017 \\
\hline Ghada Howaidy & $\begin{array}{l}\text { The role of business in society: creating space to live the } \\
\text { question within the paradox of change }\end{array}$ & 2015 \\
\hline $\begin{array}{l}\text { Andrew } \\
\text { Mountfield }\end{array}$ & Artful excursions in a complex world & 2016 \\
\hline Richard Parsons & $\begin{array}{l}\text { Theological education in the light of a contemporary } \\
\text { understanding of priestly formation and ministry: proposals for } \\
\text { action. }\end{array}$ & 2005 \\
\hline Jane Riddiford & $\begin{array}{l}\text { Enchantment and the Mechanical - An auto-ethnographic } \\
\text { inquiry into leadership framed within a cosmic and ecological } \\
\text { story }\end{array}$ & 2016 \\
\hline $\begin{array}{l}\text { Betty Ann } \\
\text { Schwarz }\end{array}$ & $\begin{array}{l}\text { Developing a standardized tool for interpretation of radiology } \\
\text { diagnostic accuracy trials. }\end{array}$ & 2016 \\
\hline Bradley Viner & Introducing clinical audit into veterinary practice. \\
\hline
\end{tabular}

Table 1. Co-researchers and their doctorate titles.

The original intention to initiate the process with an inaugural workshop, either face-to-face or virtual, was frustrated, however, on discovering that the ten who responded to our call were located across the world in many different time zones and that finding a viable meeting time would be impracticable. Therefore, we decided to operate asynchronously throughout, with the faculty group meeting occasionally by videoconference to coordinate the process. first phase of research was proposed comprising a number of initial cycles of discovery.

Stage 1

After introductions and discussion of interests, co-researchers were asked to identify areas in which we might look for impact of the degree. They were then prompted to focus on the impact of a DProf candidate on any organization and proceeded to solicit the views of coresearchers on the object of the study. The focus of the early cycles was inwards to their own organization and the indicators that might be valued within their professional domain.

Stage 2

The second cycle of inquiry yielded a potential categorization of data. The faculty group provided a consolidation of responses and identified six headings under which impact was demonstrated by the collected responses. These classes of impact were defined as:

- Specific project-related outcomes for the organisation and/or related professional networks

- Influence on policy making, strategizing and decision-making and impact on performance indicators

. 
- Own personal/professional development

- Impact from and on the "academy"

This characterisation was based on the response of one of the co-researchers which, with minor modifications, was used as the foundation for a confirmatory third cycle of inquiry.

Stage 3

In the third cycle co-researchers inspected these categories and chose those that were applicable to their context and doctoral work. They identified the impact of their research in their chosen areas with examples of how the impacts came about, how they influenced the operational or professional environment and how they felt about what was achieved. Where impact only becare evide why they believed it wa re why they believed it was related the

focus shifted subly from a that gave rise to their their new knowledge and approaches to stimulate impact in other settings.

Stage 4

Following review by the academic team of the fourth cycle responses, tentative themes were identified and so an intermediate cycle was devised to test and deepen the co-researchers unfolding narratives. Three thematic groupings were identified by the faculty team describing the modality employed to produce impacts team:

- Transformational community/professional initiatives

- Knowledge transfer

- Publication

In each case, co-researchers were provided with examples from the responses from the shared files and asked to expand on those elements or include any instances from their own experiences that they may had neglected to include previously.

Stage 5

In the fifth cycle of inquiry, focus changed from how their research influenced the original context that prompted the research to a more outward looking inquiry of how they deployed their new knowledge and approaches to stimulate impact in other settings. This subtle change of emphasis appeared to generate a new round of sense-making from the group around the themes of transformational community/professional initiatives, knowledge transfer and publication.

Stage 6

The final stage of the enquiry was to circulate a draft of the current paper to all participants prior to completion of the Discussion and Conclusions sections and seek their inputs to it.

This was undertaken in two iterations to maximise collection of responses.

Analysis and Findings

The potential classes of impact identified in the first three research cycles are identified above. Together we sought to elaborate and provide examples of impact from the alumni's doctoral and post-doctoral professional experience that show where the products of their research could be linked to impactful outcomes. There follows a brief discussion of each or the six classes of impact. the six classes of impact.
The group grappled with any definition of impact which viewed their doctoral study as a closed system or one that submitted itself to a simple cause and effect relationship. In part this was because there appeared to be little immediate impact on the organisations or on general industry-level policy from the research. This sentiment was captured by one respondent:

the question of impact, direct or indirect effects needs to be treated with caution. My dentist treated two of my teeth, on the next day I felt much better and happier signalling immediate direct impact. Yet, this treatment ought to be seen against the wider context of

$a$ 'dental treatment plan' and the totality of my personal health, indirect effect. (RP)

Researcher-practitioners work in complex and dynamic contexts where many of the problems encountered are 'wicked' in nature (Rittel \& Webber, 1973). Such problems do not lend themselves to simple solutions and cause and effect is often elusive; attempted solutions change the nature of the problem and new and unexpected consequences emerge. Wick change the nature of the problem and new and unexpected consequences emerge. Wicked problems generally entompass multiple world views, purposes and ethical positions (Brown, or sucesful discers a

Nonetheless five of the seven alumni found ways of either directly deploying the products of their research or associated insights to initiate, influence and sustain significant change initiatives either in their primary focus of attention in their home context or in closely related fields. The following examples were noted:

There was a significant direct impact within my own workplace, where the teamwork that was needed to bring about a measurable improvement in clinical performance also produced a marked and highly desirable change in practice culture. The importance of working constructively as a team to optimise outcomes became obvious, and the process helped to harbour a just learning culture. (BV)

One researcher's locus of investigation for the research was educational practices in the prison service with potential to reduce recidivism rates in the target population. She repurposed the findings from her work to address a tangentially related issue within the broader remit of her public sector organisation:

Within the organisation there is a disparity of staff receiving poor performance grades, so I created a short programme ... to support staff receiving poor or must-improve grades to consider their performance from their own perspective. (AH)

This same approach had also proven to be transferrable and impactful in other contexts. External organisations have used my services to support whole organisational approaches to new methods of working utilising and enhancing the skills of all staff within their specific area of specialism. (AH) 
The above examples indicate the capacity for practitioner-led research to produce compelling ideas that can produce changes in human and organisational systems and point to the ripple effect of ideas crossing boundaries producing unanticipated impacts.

Influence on policy making, strategizing and decision-making and impact on performance indicators

Over half the respondents proactively sought to change or shape their wider profession. Some employed traditional professional structures such as joining a governing body or council and others from the ground up "Development of environmental education charity ....[and] Attracting interest as a model of practice from other parts of the UK and abroad." (JR)

Whatever the strategy for engagement around half of the respondents could point to actions that shaped or changed policy or the nature of practice within their domain of action.

Broader societal and organisational impacts

Four of the seven respondents could point to wider community/cultural change and engagement in far reaching, largely self-generated social initiatives. It is difficult to distinguish between societal and organisational impacts as in the example above of a community regeneration charity having a strong societal impact by producing significant impact in local communities. A tangible example is provided by a respondent who pioneere an approach that has become a nationally accepted norm:

One of the projects that was spawned by my Doctorate was an online facility to benchmark postoperative complications of surgical neutering, and this is now widely recognised as one of the only profession-wide opportunities to compare and then improve standards in that way. It has now been subsumed into the Quality Improvement Advisory Board work. (BV)

Others established networks of well placed, like-minded professionals to work together to overcome inequality and reinforce justice, sound reasoning and wisdom:

The establishment of a consortium to promote women on Boards ... was built as a result of personal contacts ... whose interests converged and whose positional power in their respective organizations allowed them to leverage resources to make it happen. (GH)

The establishment of an inter-faith group of local clerics to facilitate a Transformational Community. ... to help the community to transform itself for better: less crime - amnesty for knife crimes, more housing and assisting the 'less fortunate'. $(R P)$

These examples point to a desire to utilise their reputation, network and prestige to make a difference in their community of practice.

Broader economic impact for the organisation

This is the area that offered the fewest tangible examples. The clearest one came from an educational charity initiative.

Able to charge more for our work and gain payment for different types of work, action research, leadership development, strategic input.
Development of role within the same organisations. (JR)

Own personal/professional developmen

All seven respondents cited multiple strands of evidence for their personal and professional development. All are now engaged in 'teaching' activities such as guest lecturing, assessing or as a judge in supporting, guiding and influencing colleagues within their professional spheres, including a focus on teaching as a vehicle for broader engagement with the community.

Impact from and on the "academy"

The doctoral experience generated a renewed emphasis on publication largely through traditional channels, such as books and academic and professional journals. Four of the seven respondents increased or had new publications in areas connected with their doctorate.

My main focus was in producing a book ...I have also published several peer-reviewed articles on clinical audit and clinical governance in general and spoken at several veterinary conferences on the subject. $(B V)$

Post doc I started to collaborate with the Gnosis network on art-based learning, leading to three conference / seminar contributions and a book chapter. A second book is in planning. (AM)

The greater conviction to publish can be construed as wishing to join a larger conversation about their work which is another focus of the doctoral learning. Again, the doctorate may about their work which is another focus of the doctoral learning. Again, the doctorate may
have had a smaller or larger amount of influence on what was already a desire to publish.

The final cycle

The six categories initially agreed by the group stimulated dynamic debate and surfaced many examples of personal ambition and remarkable achievement. In reviewing the experiences, a number of recurrent traits and signature practices were identified. Particularly in the latter five classes of impact the nature of the examples provided clustered around
in impacts that stemmed from the process of practitioner-research itself rather than the specific impacts that stemmed from the process of practitioner-research itself rather than the specific
products of the projects that constituted the doctoral work. They were able to utilise research products of the projects that constituted the doctoral work. They were able to ut
processes as a normal part of their repertoire to address issues as they occurred.

As the team reviewed the contributions, we began to reflect on both the problematic nature of individual influence and how we might consider the issue of whether impact can be attributed to doctoral study. As we struggled to find evidence that would substantiate direct claims of impact within the six areas initially identified by the group, we began to think about the indirect qualities of research mindedness that the writing seemed to indicate. These encompassed subtler changes of approach that may have produced a new or enhanced level or mode of practice which in turn may open a range of indirect chains of events and impacts.

Using this new lens to focus on related but indirect impacts and, specifically, impacts that were generated as a result of the processes of practitioner inquiry rather than the products of that inquiry, the faculty group proposed the following broad characteristics that early analysis that inquiry, the faculty group proposed the following broad characteristics that early analysis sugg: 
- Promotion of approaches to practitioner-research.

- Promotion of broader societal change.

- Networked, participative practice.

The fifth cycle of inquiry sought to consolidate and refine these categories using focussed questions relating to the nature of change and the detail of professional practice.

Promotion of approaches to practitioner-research

Abilities such as knowledge of research methods and reflective and reflexive thinking, which are features of the professional doctorate experience, had been incorporated into the respondents ongoing professional practice:

As I began to change my [teaching] practice, I went through a period of 12-18 months, feeling uncomfortable, as it changed my role in the classroom from expert to co-learner, feeling uncomfortable, as it changed my role in the classroom from expert to co-learner,
which exposed me to immediate feedback from participants. It was noticeable that my which exposed me to immediate feedback from participants. It was noticeable that my
approach differed significantly to those full-time academics whose teaching I experienced, approach differed significantly to those full-time acad
and that this difference was noted in classes (AM)

I gave a research workshop at our annual research conference..., presented to the I gave a research restion radiologists and research stafs on the ethics of research ........ [and] provided ethics lectures to the medical imaging students ........ my Professional Doctorate seemed to render scientific community. (BAS)

On reflective practice, one of the assignments for the Masters Programme requires students to write a reflective account of their experiences on a module - Core Competency in Pharmacy Practice, as well as on their professional practice. I hope to use my experience with completing several reflective tasks... to mark this assignment. I will also use some of the research skills I acquired in the doctoral programme, to supervise MSc projects. (CA)

Developing oneself through the vehicle of the development of others is a strong threa throughout these self-reports of impact. All seven respondents evidenced some formal teaching of discipline related material both within their parent establishments and in outreach to partner organisations.

What was perhaps more surprising was a distinct emphasis on teaching or coaching rooted in core abilities of research developed as a result of engagement with the doctoral programme. The skills of practitioner-research have become habitual to them, changed their perspective on and approach to their practice and made them advocates of a more inquiring approach to professional practice. In the words of Judi Marshall, they are "living life as inquiry" (Marshall, 2016).

Promotion of wider change

Personal change such as increasing confidence, sense of self-worth and of professionalism was evident in all responses and provided the impetus to take on new challenges and pioneer new initiatives:
Having earned a Doctorate has provided me the confidence to advance innovative research in our department that involves the use of new tools such as AI. (BAS)

The impact was both immediate, in terms of personal growth and application to Global Generation and long term, in terms of broader strategic influence. (JR)

The recognition that my qualifications have ... now enabled me to sell my practices and take on two broader roles $(B V)$

And, in some cases, the personal transformation led to a career switch and a new way of being in the world:

The impact of the doctoral process is gradually being able to see alternatives more clearly and building up the courage to take these forward. Finding the right place to jump off into something new, in my case becoming an independent advisor rather than the CEO of a consultancy. (AM)

This increase in confidence and development of professional persona is consistent with, and supportive of, previous studies (Stephenson, Malloch \& Cairns, 2006, Wellington \& Sikes, 2006, Costley \& Abukari, 2015)

Networked, participative practice

Doctoral study privileges a close, often one-to-one experience between researcher and supervisor and can become a solitary learning process. Perhaps because these profession candidates are used to operating in a range of social contexts many of them found ways of establishing their own supplementary support networks. There were unexpected examples of this need and the capacity to self-regulate:

The design of my doctoral program had peer supervision built in. We call ourselve Women at the Well... [which]... was formed during the first meeting of the doctoral cohort. We are four women from the UK, Kenya, USA and Egypt... we have been meeting physically at least four times a year, as we live in different countries, and have had weekly one-hour Skype calls. (GH)

Networking and participative practice with colleagues also continued in their post-doctoral professional practice.

Discussion

Specific new abilities derived from the doctoral process have been built into professional practice, such as research that is practitioner-led, approaches to data collection and analysis that can inform real world situations and reflective and reflexive practices. Additionally, the transdisciplinary approach of these doctorates allowed for a more holistic view of situated practice that can be difficult to achieve in a doctorate that follows a specific discipline. The practitioner-led research of the doctorate was initiated from and rooted in candidates existin and developing practice. The interactions and mutual reinforcements of a growing researchmindedness, increasing professional competence and confidence, developed abilities for impactful behaviours and outcomes. The impact was directly and indirectly related to the 
doctorate learning in that it was not solely the research driving impact, since the research itself is grounded in practice. Although there were indications that much personal change had occurred including a higher level of research-mindedness, this may be a result of some

research projects being framed in ways that had no direct impact or defined results other than the developmental change to the researchers themselves.

The process of doctoral study and gaining a doctorate brought about new-found confidence to drive wider change. There was a desire to use the new skills acquired to make a difference and to make a broader societal/ organisational impact. The finding that all recipients had been engaged in various forms of teaching raises a question about one emphasis of the doctorate being about 'learning how to learn'. If this is the case, it might be a partial explanation of why the seven respondents engaged with professional initiatives that had transformational effects on communities by helping others to learn.

Undertaking the doctorate had been mostly an isolated undertaking but, to achieve completion, change processes required that teams, networks and collegial working was necessary. This often-required practitioners to find ways to bring others along in the change process and engage more widely. It also stimulated them to engage more in publishing their work and discuss and meet with peers through a knowledge exchange process.

Some of the examples concerning reputation, networking and prestige had demonstrated difference in the ability to network successfully. The integration, development and application of research in and for professional practice required the expertise and perseverance of our co-researchers. They were senior professionals who had accrued significant amounts of professional experience prior to their doctoral studies. They then elected to undertake doctoral study whilst they continued in senior or strategic positions in their professional settings. Whether their doctoral work drove action through the abilities an approaches they had developed on the doctoral programme, or professional actions that were happening anyway or whether it was a synthesis of both is impossible to determine.

They acquired educational knowledge through practitioner-research which underpinned their professional practice. The research training part of the doctorate had a modular structure with online support, group discussions and seminars. Candidates researched their own practice rather than researching a topic remote from their professional work. These factors may have enabled them to better integrate doctoral study with their professional working lives and thus provide the opportunities to undertake relevant research within their practice settings.

An important consideration in looking at the impact of doctoral study is the length of time needed for effects to become apparent. Reporting at the time of graduation would have identified far less impact that has been revealed over the following years. It is not surprising that in programmes of this kind immediate effects may not be noticeable. The doctoral study here can be contrasted with a $\mathrm{PhD}$ by publication, for example, in which complete outcome may be publishable and published during candidature.

Finally, we have in this paper adopted a policy-driven definition of impact and applied this to individual doctoral outcomes. In doing so we were mindful that this may represent a category error of taking a systemic view and applying it at a micro-level. This proved not to be the case. We discovered that, if we avoid applying arbitrary cut-off points, such as the time of final submission, a wide range of impacts can be discerned over time, that these impacts are highly valued and celebrated by the alumni and that they influence their subsequent professional practice. The emphasis of the doctorate on learning-how-to-learn and capacitybuilding fetures appered to be a necessary feature that facilitted the impact discerned. We have demonstrated through a collaborat determine how widespread is this phenomenon.

\section{Limitations}

A study of this kind is necessarily limited by the range of co-researchers that can be involved and the experiences and programmes they represent: an intrinsic limitation of collaborative research. The other point of caution is that of attribution. Was change prompted by doctoral study or was doctoral study shaped by the context? Would some of these effects have occurred without the intervention of doctoral study. This is impossible to answer. While we have attempted to deal with this as part of the design and the continual focus on what the participants could legitimately attribute to doctoral studies, there could be other factors at play. However, the period of part-time candidature for a professional doctorate is considerably more than many organisational work assignments and therefore the influence of this will be less fleeting than many other professional activities. An addition limitation is that a collaborative enquiry of this kind does not allow for the validation of self-report data by others. Further study is needed to determine whether others in the orbit of the alumni have been influenced in the ways identified.

\section{Conclusions}

The engagement of alumni as co-researchers has enabled an exploration of the impact of work-oriented professional doctorates. Impact was found not to arise from particular products or achievements of the doctorate itself, but on the processes and habits of mind engendered in the doctoral process. The effects identified were ones of building and strengthening capacity of candidates as manifest through contributions to working with and fostering the development of colleagues and enhancing their professional area.

\section{References}

Armsby, P. M., Costley, C. \& Cranfield, S. (2018) The design of doctorate curricula for practising professionals. Studies in Higher Education, 43, 12, 2226-2237.

Boud, D., Fillery-Travis, A., Pizzolato, N. \& Sutton, B. (2018) The influence of professiona doctorates on practice and the workplace. Studies in Higher Education, 43, 5, 914-926. Brown, V. A., Harris, J. A., and Russell, J. Y. (2010) Tackling Wicked Problems Through Transdisciplinary Imagination. London: Routledge.

Coghlan, D. (2007) Insider action research doctorates: Generating actionable knowledge. Higher Education 54:293-306

Coleman, G. (2019) Action Research. In Costley, C. \& Fulton, J. (Eds.) Methodologies for Practice Research (pp.151-172) London: Sage.

Costley C. \& Abukari, A. (2015) The impact of work-based research projects at postgraduate level. Journal of Work-Applied Management 7, 1, 3-14.

Drew, V., Priestley, M., \& Michael, M. K. (2015) Curriculum development through critical collaborative professional enquiry. Journal of Professional Capital and Community, 1, 1 , 92-105.

East, L., Stokes, R. \& Walker, M. (2014) Universities, the public good and professional education in the UK. Studies in Higher Education 39, 9,1617-1633.

ERA (2018) Excellence in Research Australia https://www.arc.gov.au/engagement-andimpact-assessment 
ESRC (2019a) Economic and Social Research Council (UK) What is impact? https://esrc.ukri.org/research/impact-toolkit/what-is-impact/

ESRC (2019b) Economic and Social Research Council (UK) Developing pathways to impact. https://esrc.ukri.org/research/impact-toolkit/developing-pathways-to-impact/

Fox, A \& Slade, B . (2014) What impact can organisations expect from professional doctorates? Professional Development in Education 40, 4, 546-560.

Greenwood, D. J. and Levin, M. (2007) Introduction to Action Research (2nd Ed). London Sage.

Hawkes, D. \& Yerrabati, S. (2018) A systematic review of research on professional doctorates, London Review of Education, 16, 1, 10-27.

Kumar, S., (2014). A systematic approach to the assessment of impact in a professional doctorate. Higher Education, Skills and Work-based Learning, 4, 2, 171-183.

Lee, A., Brennan, M. \& Green, B., (2009). Re-imagining doctoral education: professiona doctorates and beyond. Higher Education Research \& Development, 28, 3, 275-287.

Lester, S. (2012) Creating original knowledge in and for the workplace: evidence from a practitioner doctorate, Studies in Continuing Education 34, 3, 267-280.

McSherry, R., Bettany-Saltikov, J., Cummings, E., Walker, K. Ford, K. \& Walsh, K. (2019) Are you measuring the impacts and outcomes of your professional doctorate programme? Studies in Continuing Education, 41, 2, 207-225.

Mellors-Bourne, R., Robinson, C. \& Metcalfe, J. (2016) Provision of Professional Doctorates in English HE Institutions. Cambridge: Careers Research and Advisory Centre.

Perry, J. A. \& Zambo, D. (2018) Themed section of Impacting Education focused on CPED's Principle. Impacting Education: Journal of Transforming Professional Practice, 3, 2, 17

Rittel, H.W.J. \& Webber, M.M. (1973) Dilemmas in a general theory of planning. Policy Sciences, 4, 155-169.

Stephenson, J., Malloch, M. \& Cairns, L. (2006) Managing their own programme: a case study of the first graduates of a new kind of doctorate in professional practice. Studies in Continuing Education, 28, 1, 17-32.

Townsend, A. (2013) Action Research: The Challenges and Understanding of Changing Practice. Maidenhead: Open University Press.

UKRI (2016) UK Research and Innovation. https://www.ukri.org/innovation/excellencewith-impact/

Wellington, J \& Sikes, P. (2006) A doctorate in a tight compartment': why do students choose a professional doctorate and what impact does it have on their personal and professional lives? Studies in Higher Education 31, 6, 723-734. 